\title{
Does beauty have a price? The impact of a conceptualization of beauty on the price placebo effect in Turkey compared to New Zealand
}

\author{
Djavlonbek Kadirov \\ School of Marketing and International Business, \\ Victoria University of Wellington, Wellington, New Zealand \\ Charleen Raju \\ Victoria University of Wellington, Wellington, New Zealand \\ Ahmet Bardakc1 and Nazan Madak \\ Pamukkale University, Denizli, Turkey, and \\ Mohammad Saud Khan \\ Victoria University of Wellington, Wellington, New Zealand
}

\begin{abstract}
Purpose - Marketers of beauty products capitalize on consumers' perception of beauty to enact a price placebo effect through setting high prices to insinuate a superior performing product. Yet, in the context of growing alternative beauty movements emphasizing inner beauty and self-acceptance, little is known on how the effect of price on a product's perceived effectiveness and satisfaction is bounded by different modes of beauty conceptualization (BC). Hence, this study aims to investigate how distinct perceptions of beauty impact the effectiveness-based and satisfaction-based price placebo effects in Muslimmajority markets such as Turkey compared to markets largely driven by Western values such as New Zealand.

Design/methodology/approach - This research is based on a quasi-experimental factorial design based on the manipulation of the level of price for a beauty product and the observation of the extent of BC. The sample included 144 participants from Turkey and 147 participants from New Zealand.

Findings - This research finds that the manipulation of the price (low vs high) equally activates the effectiveness-centered price placebo effect in both countries. When expectations are taken into account, the (satisfaction-based) price placebo effect is non-existent in New Zealand, while in Turkey the higher price leads to an opposite effect: a significant decrease in satisfaction. It is also found that the effect of price on effectiveness is moderated by $\mathrm{BC}$. In both countries, the price placebo effect is activated only when consumers narrowly conceptualize beauty, while this effect does not hold for broad conceptualizers. The effect of $\mathrm{BC}$ on the price placebo appears to be stronger in New Zealand in comparison to Turkey.

Practical implications - Marketing managers' awareness of different perceptions of beauty and how these may influence the price placebo effect in different cultures would allow them to decide what strategies are most appropriate for different groups of customers. For example, by pursuing the movement toward inner beauty and its broad conceptualization, high-end brands are likely to compromise opportunities to capitalize on the price placebo effect. On the other hand, this alternative perspective may cultivate profound satisfaction in the long-term.
\end{abstract}

Impact of a conceptualization of beauty

Received 3 June 2019 Revised 20 April 2020 Accepted 21 April 2020 
Social implications - The price placebo effect disappears when people conceptualize beauty from a broad (inner) perspective. This suggests that public policymakers, to counteract the negative effects of misleading marketing and to create fair exchanges, must promote broad BC in society.

Originality/value - This study contributes to the body of the existing research on price placebo by offering unique insights into the boundary conditions of the price placebo effect underscored by $\mathrm{BC}$ in two distinct cultural-religious settings. Also, it proposes two different variations of price placebo, namely, effectiveness-centered vs satisfaction-centered. From a methodological point of view, it is the first project in the Islamic marketing discipline that applies the Islamic perspective on causality.

Keywords Price, Islamic markets, Cosmetics, Islamic markets, Islamic pharmaceuticals, Beauty products, Price placebo, Fashion, Causality in Islam

Paper type Research paper

\section{Introduction}

Beauty regimes are ingrained into human nature: their impact was observed from as early as 10,000 BC and continues to hold importance in modern societies (Chaudhri and Jain, 2014; Havlin and Báez, 2018). Beauty related behavior tends to be ritualistic: some individuals wear cosmetics on a daily basis. This may be because of perceptions of beauty being associated with cosmetic usage and without it, beauty seeming unattainable. Such social impressions are pioneered by beliefs supporting Roman philosopher Plautus' view that "a woman without paint is like food without salt" (French, 2004, p. 1). In spite of these views existing in pre-historic times, these impressions appear to be still relevant in modern society. However, an alternative view also exists expressed in idioms such as "beauty is only skin deep." Specifically, holism is a key dimension for Muslims using cosmetic brands (Aoun and Tournois, 2015).

The global cosmetic industry is growing at an average rate of $6.4 \%$ and is predicted to increase from the current US $\$ 460 \mathrm{bn}$ to US $\$ 675 \mathrm{bn}$ by 2020 (Business Wire, 2015). The skin care industry commands the highest share of the market with a value of US\$134bn, while it is expected to reach US\$180.3bn in 2024. Currently, this industry tends to promote a narrow view of beauty based on physical appearance (Scherker, 2014). People are using cosmetics at an increasingly younger age, while their expectations of beauty are often shaped by digitally altered images. Researchers talk about "snapchat dysmorphia," the younger generation being susceptible to excessive preoccupation with perceived flaws in appearance (Fried et al., 2020; Rajanala et al., 2018). Using digitally enhanced images created via "photoshopping" and now easily accessible selfie-editing technology, the skin care industry capitalizes on such trends. In some cases, marketing is so drastic that the Advertising Standards Authority in the UK, for example, ruled that because of some model images being so heavily retouched, the advertising under focus was deemed misleading (Thompson, 2020). Unrealistic beauty standards significantly impact the behavior of consumers: women report that they feel dissatisfied with own physical appearance after watching advertisements (Hargreaves and Tiggemann, 2002; Owens, 2016; MacCallum and Widdows, 2018).

In contrast, the value of inner beauty, self-acceptance and holism has started to gain attention in the cosmetics industry (McKelle, 2015). Driven by ethical responsibility and, perhaps, profit-generation, some marketers are following a new trend. One widely known campaign was the "dove campaign for real beauty" that challenged the typical thin models and included real women physiques conveying that everyone is beautiful (Huffington Post, 2014). The pioneering campaign generated masses of viral attention that it was awarded the "\#1 Ad for the 21st-century by Ad Age (Duan, 2015). Leading this movement, numerous campaigns followed Dove, including CoverGirl's \#GirlsCan, Pantene Philippines" "Labels Against Women," Gillete Venus' \#UseYourAnd and DoveHair "Love Your Curls” (Duan, 2015). These campaigns demonstrate the movement away from the mainstream beauty perceptions by 
encompassing the appreciation of inner beauty. Moreover, in Muslim societies struggle against the hegemonic pressure of Western beauty ideals is reflected in a new stream of Islamic brands such as HijUP that focus on authentic inner feelings (Wilson, 2016).

The dilemma for marketers is whether the holistic approach will be as feasible in the long run in generating profits as the traditional outer beauty approach. Specifically, high-end skin care brands employ effective price strategies enacting the price placebo effect (Shiv et al., 2005; Irmak, Block and Fitzsimons, 2005; Borsook and Becerra, 2005). The effect is counter-intuitive: perceived product performance depends on a price level (Shiv, Carmon and Ariely, 2005). Marketers commonly use this strategy setting high prices to insinuate a superior performing product (Leavitt, 1954). However, no research has so far examined how differing perceptions of beauty impact the price placebo effect. In other words, the existing research has not extended to investigate how the impact of price level on a product's perceived effectiveness is bounded by different modes of beauty conceptualization (BC). Moreover, is this moderating effect the same for markets with a Muslim majority vs those with a Muslim minority? Closing this gap will provide an insight to practitioners on whether consumers' beauty perceptions are an important consideration when pricing products and if so, how consumers are likely to respond to different levels of prices in different contexts. Therefore, the primary objective of this study is to examine whether the price placebo effect exists in relation to both product effectiveness and satisfaction, and how such effects are influenced by individuals' perception of beauty in different cultural contexts.

\section{Theoretical background}

\subsection{Price placebo}

A conventional placebo refers to an inert substance, which is used as a semblance of active medication, yet has no medicinal properties effecting the condition being treated (Kirsch, 1985; Sölle et al., 2014; Price et al., 2008; Geers et al., 2005). The effect occurs when the patients experience the benefits of the medication they believe to have been treated with (Shiv et al., 2005; Stewart-Williams and Podd, 2004). Two approaches have been recognized in explaining how the effect occurs: classical conditioning and the expectancy theory (Stewart-Williams and Podd, 2004; Montgomery, 1997). Classical conditioning is the notion that active medication with known effects serve as the unconditioned stimuli and the vehicles they are delivered in - methods and techniques - are the conditioned stimuli (Geers et al., 2005). Over time, it is believed that conditioned responses are evoked when the two are paired, creating a placebo effect (StewartWilliams and Podd, 2004; Montgomery, 1997; Geers et al., 2005). While the expectancy theory states that because of pre-conceived expectations - which can be formed through previous experiences - salient beliefs of a substance can create a placebo effect through anticipation of the expected outcome (Stewart-Williams, 2004; Geers et al., 2005). For example, a substance perceived to be an analgesic may incidentally reduce physical pain (Montgomery and Kirsch, 1996; Vase et al., 2003) or treat mental disabilities (Kirsch and Sapirstein, 1998).

The placebo literature has also been extended to address marketing activity, in particular the price-placebo effect. The price placebo effect, comparable to the original placebo effect, is demonstrated when the price of a substance influences its performance, i.e. the efficacy of the outcome (Shiv et al., 2005; Irmak et al., 2005; Borsook and Becerra, 2005). The expectancy theory mentioned above is attributable in this marketing context, where individuals use price to create expectations before using the product (Shiv et al., 2005). These expectations hold considerable weight, which affects the product efficacy and make the outcome subjective to the individual's expectations and beliefs of the product. This discovery was established by Shiv et al. (2005), where the price of an energy drink was used to influence actual performance - mental acuity in puzzle solving. It was found that the energy drink 
with the discounted price exhibited lower levels of effectiveness. Additionally, when the price-placebo effect was mentioned, the effect diminished, suggesting the placebo effect is a subconscious occurrence (Shiv et al., 2005).

The research to date focused on actual effectiveness, while the existence of the price placebo effect with regard to perceived effectiveness would still need to be examined. This is important because for some products, effectiveness is largely based on consumer perceptions and expectations. This happens because of actual performance being difficult to assess. For example, in the context of beauty products, the effectiveness of how a skin care product improves the skin is mostly perceptual.

We consider two types of perceptual price placebo, namely, effectiveness-centered price placebo and satisfaction-centered price placebo. Taking the Islamic methodological perspective to theory building, we argue that the price placebo effect is activated because of Allah's (swt) established Sunnah in the human nature, which is reflected in striving toward a perceptual balance between value gained (i.e. benefit) and value forsaken (i.e. price) (Kadirov et al., 2020). Such expectation of balance is reflected in perceptions of justice in markets (Kadirov, 2018), price-quality schema (Lichtenstein and Burton, 1989) and signaling theory. Other things being equal, a higher-priced product is likely to subconsciously lead to greater perceived effectiveness at a time of evaluation. We expect that high price would lead to greater expectations, which are subconsciously transformed into effectiveness perceptions. If we compare expectations to effectiveness, another type of perceptions emerges: satisfaction. Satisfaction is perceptual too: it is linked to the interaction between perceived effectiveness and prior expectations. Satisfaction is defined as the difference between effectiveness and expectations (Fearon and Philip, 2008). This definition is at the heart of the expectations-disconfirmation paradigm (Zehrer et al., 2011; Suciu et al., 2013). This study proposes a mechanism for the incidence of satisfaction-centered price placebo. A low priced product is likely to result in negative disconfirmation (or a neutral state) when perceived effectiveness is less (or equal to) expectations. For the satisfaction-centered price placebo effect to be present, the high priced product will most likely result in positive disconfirmation, where perceived effectiveness exceeds expectancy levels (Santos and Boote, 2003; Fearon and Philip, 2008). We expect that because the Sunnah of Allah (swt) concerning perceptual balance operates as a stable human nature, both New Zealand and Turkey contexts are likely to exhibit the price-placebo effect (Kadirov et al., 2020).

H1a. Consistent with the Sunnah of Allah (swt), effectiveness-centered price placebo is likely to operate in both socio-cultural settings.

H1b. Consistent with the Sunnah of Allah (swt), satisfaction-centered price placebo is likely to operate in both socio-cultural settings.

\subsection{Beauty conceptualization}

Beauty is a complex concept that is perceived differently in different contexts and circumstances (Tylka and Iannantuono, 2016). We distinguish two types of BC, namely, broad and narrow. An individual who broadly conceptualizes beauty recognizes differing physical appearances as beautiful and draws beauty from both inner and outer characteristics. The outer characteristics involve physical attractiveness, whereas, inner characteristics include personal facets such as personality and confidence (Tylka and WoodBarcalow, 2015; Tylka and Iannantuono, 2016). When beauty is conceptualized positively and broadly, it can enrich the personal experience and promote a wise understanding and acceptance of differing body types (Tylka, 2012; Cook-Cottone, 2015). It can also help 
recognize that media-promoted beauty is only one form of physical attractiveness (Tylka and Wood-Barcalow, 2015a). On the other hand, the narrow conceptualization of beauty involves a focus on outer beauty and external characteristics only.

Media tends to promote the narrow conceptualization as an "ideal image" (Yan and Bissell, 2014). Research suggests that people who are susceptible to the narrow conceptualization are often affected by media images (Tylka and Iannantuono, 2016). Media communications including advertising exhibiting physically attractive models are more likely to influence those concerned with outer beauty than broad conceptualizers who are likely to be less attentive. It is expected that $\mathrm{BC}$ will influence the price placebo effect. As narrow conceptualizers are more likely to perceive relevant products to be more effective under the high price condition, the effectiveness-centered price placebo is likely to become activated. However, broad conceptualizers, who would not perceive effectiveness as greatly as narrow conceptualizers, may experience no placebo effect.

Similarly, in regard to satisfaction-centered price placebo, we expect that the relationship between price and satisfaction will also be determined by the nature of $\mathrm{BC}$. Narrow conceptualizers are likely to experience the confirmation of expectations, as their perceived effectiveness and expectations would more or less match. However, broad conceptualizers can be expected to be somewhat dissatisfied, as their expectations may significantly exceed their effectiveness perceptions. This creates an undesirable placebo effect: the low price is likely to create dissatisfaction (Shiv et al., 2005). This type of price placebo is linked to dissatisfaction, as an increase in price may lead to a decrease in satisfaction for broad conceptualizers.

H2a. Consistent with the Sunnah of Allah (swt), BC is likely to impact the incidence of the effectiveness-centered price placebo (the effect is likely to appear only in the narrow $\mathrm{BC}$ condition).

$H 2 b$. Consistent with the Sunnah of Allah (swt), BC is likely to impact the incidence of the satisfaction-centered price placebo (the effect is likely to appear only in the narrow BC condition).

\section{Method}

\subsection{Design and participants}

The data was collected in New Zealand and Turkey. The quasi-experimental design was conducted through the survey platform qualtrics. The experimental set-up was a two (price: high vs low $) \times$ two (BC: broad vs narrow) between-subjects design. Only the price condition was manipulated, while the broad and narrow $\mathrm{BC}$ conditions were created by splitting the sample into two groups from the observed mean. The respondents were randomly assigned to each condition through a randomization function on qualtrics. Once clicking on the link provided on either Facebook or Reddit, the respondent was redirected to an information sheet. After providing consent the respondent would press the next button and continue with the survey. At the beginning of each condition, a hypothetical scenario was described showing a high price or a low price. The scenario read:

In this survey you will be presented an image of a consumer who has been using an anti-aging moisturizer for the past 6 months consistently. The price of this product was $\$$ _. Please use this information to answer the following questions.

The price in the high priced condition used a $\$ 400$ product, whereas the low priced condition used a $\$ 20$ product. These price levels were chosen because skin care products on average
Impact of a conceptualization of beauty

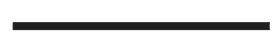


range from $\$ 10-\$ 500$ (Lifecellproducts, 2013). Additionally, a consumer was referred to in the scenario rather than having the respondent identify themselves as the consumer. This was done because the survey included an objective image used to assess perceived effectiveness. By having all respondents in both conditions presented with an identical image, it controlled for any variances in the images. Also this removed any biases or opinions on what the respondent believed was an appropriate amount for themselves to spend on a skin care product. As a result, external factors were controlled for and the only difference in both conditions were the price manipulations. The participants were also told to use the scenario to answer the additional questions in the survey.

A total of 170 responses were collected in New Zealand. However, after close examination only 147 of these were assessed to be usable, and thus retained. Responses were removed because of several reasons: missing a response, not falling within the sampling frame or invalid response. The sample targeted for this survey was anyone above the age of 16 to avoid ethical concerns for targeting younger vulnerable audiences (Palmer and Hedberg, 2013). Any data that was collected from participants under the age of 16 were deleted and not used in the data analysis. The larger age bracket was used, as it allowed greater reliability and validity of the study and increases generalizability. There was no other criterion for participation and all demographics were able to participate. This allowed for better representation of the population. For experimental designs, Lenth (2001) suggests having a minimum of 23 respondents per condition. As this design considered a two (price) $\times$ two $(\mathrm{BC})$ factorial design, a minimum of approximately 100 participants was required. However, to ensure optimal reliability when generalizing the findings, it seemed appropriate to aim for a higher sample size to provide room for error.

An online method of data collection was selected as the internet allowed for greater distribution of the survey and was also accessible to a wider range of the population. Likewise, it was more convenient for respondents to access the online survey from any location rather than physically going to a certain location, thus, was also cost-effective (Evans and Mathur, 2005). Another strength of online data collection was the speed and ease of data entry (Evans and Mathur, 2005) (Ilieva et al., 2002). This channel was chosen as New Zealand statistics show that in 2012, 80\% of homes in New Zealand had some form of connection to the internet (Statistics New Zealand, 2013). Furthermore, statistics indicate that New Zealanders have demonstrated a $30 \%$ increase in mobile internet and smartphone usage all in one year (Statistics New Zealand, 2013). The survey was also compatible with mobile devices which would increase convenience and accessibility from any location. Minimizing the effort required to access the survey was done to encourage participation. The survey was distributed through Facebook and Reddit. These social platforms are generally recognized as being appropriate channels for sharing public posts. Facebook was chosen as 1.9 million New Zealanders use Facebook daily (NZ Herald, 2015) indicating respondents being highly accessible. Reddit was chosen as it specified pages are created for survey sharing purposes.

The posts requested participants to refer the survey onto their acquaintances - Facebook friends were requested to share the link to their own friends - which created a snow-balling effect. The sample size gradually increased and was completely random. The survey was not posted on University portals such as Victoria University of Wellington's Blackboard portal as this would have skewed the sample toward students. As students are more pricesensitive than the general population (Litman, 2004), this would have created a bias in the price-perception aspect of this study, more importantly in the low priced condition. Once the survey was completed and submitted, the data was easily attainable by the researcher. Similarly, as a statistical package for the social sciences (SPSS) was used for the data 
analysis, data was exported directly from qualtrics into the SPSS software increasing the efficiency. The anonymity of the survey was another key benefit. As no personal questions or physical interaction occurred, identifying the respondents was not feasible. This assurance of anonymity may have encouraged some respondents to participate in the survey and also provide genuine responses. The same design was applied in Turkey. The survey was translated into Turkish and then back-translated into English to remove inadequacies. In total, 144 university students, administrative and academic staff participated in the study. The participants were approached by trained research associates and the survey was completed using a face-to-face method. No incentives were offered for participation.

\subsection{Measures}

The constructs, namely expectations, perceived effectiveness and $\mathrm{BC}$ were operationalized based on the previous research. Price was the manipulated condition. The scales were adapted to make them relevant in a skin care context and all consisted of a six-point scale being either a Likert-scale or a semantic differential scale. The points on each scale were kept consistent to represent the same degree of agreement/disagreement for each item. The list of scales is given in Table 1.

The construct expectations was borrowed from Roggeveen et al. (2007). For the purposes of the current study, the items were adapted to a skin care context. The scale had a Cronbach's alpha value of 0.92 (Roggeveen et al., 2007). For the current study, the items were measured on a six-point Likert-scale and anchored by "strongly disagree" (1) and "strongly agree" (6).

The perceived effectiveness construct was based on Voss et al. (2003) who examined consumer attitudes toward utilitarian and hedonic dimensions. The construct was further developed and validated by Kleijnen, de Ruyter and Wetzels' (2007) study, where the functional value of a product was measured. The Cronbach's alpha was 0.95 or above confirming high reliability (Saunders et al., 1993). The construct had eight items, however, for the purpose of this study only seven were adopted. Seven six-point semantic differential scales were used to measure this construct (Kleijnen et al., 2007).

The $B C$ construct was based the recently developed construct of broad conceptualization of beauty by Tylka and Iannantuono (2016). They examined the degree to which women conceptualize beauty through physical characteristics such as body shapes and appearances as well as inner beauty characteristics such as confidence and self-acceptance. Being a newly developed scale, the reliability was measured in two different studies. The internal consistency measured in three different sample groups all demonstrated a Cronbach's alpha of 0.85 or higher and the second study obtained a Cronbach's alpha of 0.88 . These scores represent good internal consistency (Gliem and Gliem, 2003), which is important to identify in newly developed scales. Although the scale originally contains nine items, some items were discounted to best suit the study. The items that were used in the current study were as follows.

Four control variables were included in the model, namely, involvement, gender, age and usage. Involvement is included as a control variable in the current study. It was measured on a six-point Likert-scale with four items measuring participants' involvement with skin care products. The items were anchored by "strongly disagree" (1) and "strongly agree" (6). The scale was adopted from Coulter et al. (2003) who have amalgamated involvement scales originally created by Zaichkowsky (1994) and Higie and Feick (1989). Again, this scale has no record of validation. The reliability of the scale met a Cronbach's alpha of 0.92 and 0.94 in the two recorded studies (Coulter et al., 2003; Micu et al., 2009) portraying high reliability. 


\begin{tabular}{|c|c|c|c|}
\hline Constructs & Items & Scale & $\alpha$ \\
\hline Expectations & $\begin{array}{l}\text { I anticipate that the consumer will be satisfied with } \\
\text { the functionality of the skin care product she has } \\
\text { purchased. } \\
\text { I expect that the consumer will be happy about her } \\
\text { decision to purchase this skin care product. } \\
\text { I believe that the consumer did the right thing by } \\
\text { purchasing this skin care product. } \\
\text { Overall, I expect that she should be satisfied with } \\
\text { this product. }\end{array}$ & $\begin{array}{l}\text { Roggeveen } \\
\text { et al. }(2007)\end{array}$ & 0.920 \\
\hline $\begin{array}{l}\text { Perceived } \\
\text { effectiveness }\end{array}$ & $\begin{array}{l}\text { Effectiveness - anchored by "not at all effective" (1) } \\
\text { and "very effective" (6) } \\
\text { Functionality - anchored by "not functional" (1) and } \\
\text { "functional” (6) } \\
\text { Practicality - anchored by "not practical" (1) and } \\
\text { "very practical" (6) } \\
\text { Usefulness - anchored by "not useful" (1) and "very } \\
\text { useful" (6) } \\
\text { Efficiency - anchored by "not efficient" (1) and "very } \\
\text { efficient" (6) } \\
\text { Productivity - anchored by "not productive" (1) and } \\
\text { "very productive" (6) } \\
\text { Good/bad - anchored by "bad" (1) and "good" (6) }\end{array}$ & $\begin{array}{l}\text { Voss et al. } \\
(2003)\end{array}$ & 0.950 \\
\hline $\mathrm{BC}$ & $\begin{array}{l}\text { Even if a physical feature is not considered attractive } \\
\text { by others or by society, I think that it can be } \\
\text { beautiful. } \\
\text { A woman's confidence level can change my } \\
\text { perception of her physical beauty. } \\
\text { A woman's soul or inner spirit can change my } \\
\text { perception of her physical beauty. } \\
\text { I define a woman's beauty differently than how it is } \\
\text { portrayed in the media. } \\
\text { A woman's acceptance of herself can change my } \\
\text { perception of her physical beauty. } \\
\text { I appreciate a wide range of different looks as } \\
\text { beautiful. } \\
\text { I think that women of all body sizes can be beautiful. }\end{array}$ & $\begin{array}{l}\text { Tylka and } \\
\text { Iannantuono } \\
(2016)\end{array}$ & 0.880 \\
\hline Involvement & $\begin{array}{l}{[\ldots] \text { are interesting to me }} \\
{[\ldots] \text { are fascinating to me }} \\
{[\ldots] \text { are important to me }} \\
{[\ldots] \text { are exciting to me }}\end{array}$ & $\begin{array}{l}\text { Zaichkowsky } \\
\text { (1994) }\end{array}$ & 0.94 \\
\hline
\end{tabular}

Only four items were selected as they were the most relevant and directly applicable to a skin care context. Additionally, to encourage survey completion the survey was kept short as longer surveys have a higher abandonment rate (Crawford $e t$ al., 2001). The reverse item "are boring to me" was adapted to "are interesting to me" to avoid any confusion and to ensure that all points on every scale measure the same degree of agreement. Moreover, completing the essential questions, the respondents further stated their involvement with skincare products, how often they used them, their gender and their age. These measures served as covariates during the statistical analysis. A manipulation check was also conducted through the question "do you consider this product to be a high priced anti-aging moisturizer/low priced anti-aging moisturizer" to ensure respondents perceived their 
assigned price as what the research intended. Those who did not perceive the price as the study intended were disregarded during the data analysis.

Impact of a conceptualization of beauty

\section{Results}

\subsection{Effectiveness-centered price placebo}

For the New Zealand sample, we find that the main effect of price level on perceived effectiveness to be significant $\left[F(1,137)=5.96, p<0.05, \mathrm{~h}^{2}=0.04\right]$. The same effect is true for Turkey as well $\left[F(1,119)=4.49, p<0.05, \mathrm{~h}^{2}=0.04\right]$. Hence, $H 1 a$ is supported: the effectiveness-centered price placebo effect exists in both New Zealand and Turkey. Also, we find that the main effect of $\mathrm{BC}$ on effectiveness to be significant in both New Zealand $[F(1$, $\left.137)=14.61, p<0.01, \mathrm{~h}^{2}=0.10\right)$ and Turkey $\left(F(1,119)=4.99, p<0.05, \mathrm{~h}^{2}=0.04\right]$.

We find a significant interaction effect in New Zealand $\left[F(1,137)=4.15, p<0.05, \mathrm{~h}^{2}=\right.$ 0.03]. This means that $\mathrm{BC}$ moderates the effect of price level on effectiveness. The same pattern is observed in Turkey as well $\left[F(1,119)=2.69, p<0.10, \mathrm{~h}^{2}=0.02\right]$. The nature of this moderation effect is as follows: the effectiveness-centered price placebo operates only in the narrow $\mathrm{BC}$ condition, while there is no price placebo effect is the broad $\mathrm{BC}$ condition (Figure 1). $H 2 a$ is supported.

The simple-effect tests confirm this result. In New Zealand, the price placebo effect is strong in the narrow $\mathrm{BC}$ group. The average effectiveness level in the high price condition $(M=4.68, \mathrm{SE}=0.27)$ is significantly greater than that in the low price condition $(M=3.74$, $\mathrm{SE}=0.19)$. This difference is significant $\left[F(1,137)=8.22, p<0.01, \mathrm{~h}^{2}=0.06\right]$. The similar effect can be observed in Turkey: low price $(M=3.02, \mathrm{SE}=0.18)$ vs high price $(M=3.80$, $\mathrm{SE}=0.15)$. This effect is also significant $\left[F(1,119)=10.21, p<0.01, \mathrm{~h}^{2}=0.08\right]$. However, there appears to be no price placebo effect in the broad BC group. In New Zealand, the average effectiveness level in the low price condition $(M=3.35, \mathrm{SE}=0.21)$ and the high price condition $(M=3.44, \mathrm{SE}=0.15)$ are not significantly different $\left[F(1,137)=0.11, p=0.74, \mathrm{~h}^{2}=\right.$ $0.001]$. For the Turkish sample, this pattern is repeated: low price $(M=3.82, \mathrm{SE}=0.24)$ vs high price $(M=3.91, \mathrm{SE}=0.23)$, where the effect is not significant $[F(1,119)=0.08, p=0.77$, $\left.\mathrm{h}^{2}=0.001\right]$.

We also used Hayes process (Hayes, 2013) to test the interaction involving the BC variable measured on a metric scale. In new Zealand, the interaction is found to be significant $[t(129)=-2.50, p<0.01,95 \% \mathrm{CI}-1.27,-0.15]$. The Johnson-Neyman significance region test showed that price placebo comes into effect when $\mathrm{BC} \geq 5.04$, which is essentially the mean value. This finding also supports our decision to split the sample using the mean value as a threshold. In contrast, for the Turkish sample the Hayes process analysis resulted in an insignificant effect $[t(111)=-1.47, p=0.14,95 \% \mathrm{CI}-0.95,0.14]$.

New Zealand

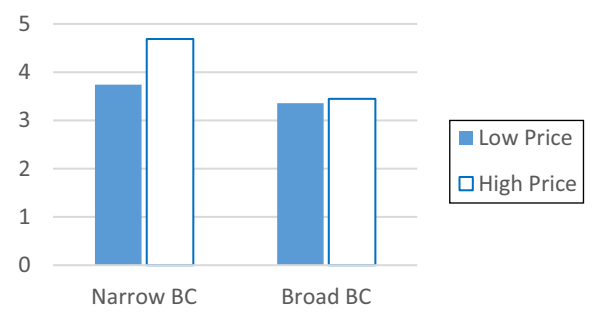

Turkey

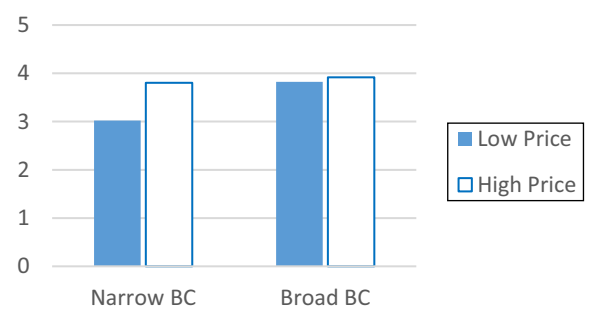

Figure 1. Effectivenesscentered price placebo depends on 


\subsection{Satisfaction-centered price placebo}

There appears to be no satisfaction-centered price placebo in New Zealand, as the main effect of the price level is insignificant $\left[F(1,137)=0.18, p=0.67, \mathrm{~h}^{2}=0.001\right]$. In contrast, this price placebo exists in Turkey $\left[F(1,119)=6.09, p<0.05, \mathrm{~h}^{2}=0.05\right]$. Therefore, it can be said that $H 1 b$ is partially supported. Moreover, the nature of satisfaction-centered price placebo appears to be based on negative disconfirmation. In other words, the high price condition is characterized with a greater level of dissatisfaction.

Confirming $H 2 b$, we find a significant interaction effect in both New Zealand $[F(1,137)=$ $\left.3.24, p<0.10, \mathrm{~h}^{2}=0.02\right]$ and Turkey $\left[F(1,119)=3.46, p<0.10, \mathrm{~h}^{2}=0.03\right]$. BC does indeed moderate the effect of price on satisfaction (Figure 2). In New Zealand, high price (vs low price) tends to lead to greater satisfaction among narrow conceptualizers, while this factor (high vs low price) tends to aggravate dissatisfaction among broad conceptualizers. In Turkey, for narrow conceptualizers, dissatisfaction increases in the high price condition, while satisfaction turns into dissatisfaction for broad conceptualizers.

The simple-effect tests confirm this. For the New Zealand sample, in the narrow BC group positive disconfirmation is greater for the high price condition $((M=0.53, \mathrm{SE}=0.28)$ compared to the low price condition $(M=0.03, \mathrm{SE}=0.20))$. However, this effect did not reach significance $\left[F(1,137)=2.03, p=0.16, \mathrm{~h}^{2}=0.001\right]$. For the broad $\mathrm{BC}$ group, negative disconfirmation is greater for the high price condition $[(M=-0.61, \mathrm{SE}=0.16)$ vs the low price condition $(M=-0.31, \mathrm{SE}=0.22)]$. Yet again, the effect did not reach significance $[F(1$, $\left.137)=1.20, p=0.27, h^{2}=0.001\right]$. For the Turkish sample, the narrow BC group exhibit negative disconfirmation, which is greater for the high price condition $[(M=-0.70, \mathrm{SE}=$ $0.15)$ vs the low price condition $(M=-0.58, \mathrm{SE}=0.18)]$. However, the effect did not reach significance $\left[F(1,119)=0.24, p=0.62, \mathrm{~h}^{2}=0.002\right]$. The Broad $\mathrm{BC}$ group exhibited the following effect: positive disconfirmation in the low price condition $(M=0.12, \mathrm{SE}=0.24)$ turns into negative disconfirmation in the high price condition $(M=-0.77, \mathrm{SE}=0.22)$. The effect was significant $\left[F(1,119)=7.15, p<0.01, \mathrm{~h}^{2}=0.06\right]$.

The analysis based on Hayes process (Hayes, 2013) involving the metric measure of BC indicated that the interaction is significant $[t(129)=-1.79, p<0.10,95 \% \mathrm{CI}-1.11,0.06]$ in New Zealand. The Johnson-Neyman method did not reveal any significance transition points. In Turkey, the analysis shows that the interaction is not significant $[t(111)=-1.39$, $p=0.17,95 \% \mathrm{CI}-0.94,0.17]$.

\subsection{Cultural differences}

We observed that, for narrow conceptualizers, perceived effectiveness is greater in $\mathrm{NZ}(M=$ $4.0, \mathrm{SD}=1.14, N=54)$ compared to Turkey $(M=3.42, \mathrm{SD}=1.12, N=86)$. This difference is significant $[t(138)=2.94, p<0.01]$. At the same time, for broad conceptualizers perceived effectiveness was greater in Turkey $(M=3.97, \mathrm{SD}=1.09)$ compared to NZ $(M=3.44, \mathrm{SD}=$ $1.25)$ and this difference was significant $[t(124)=2.33, p<0.05]$. In regard to satisfaction,

Figure 2.

Satisfaction-centered price placebo depends on $\mathrm{BC}$
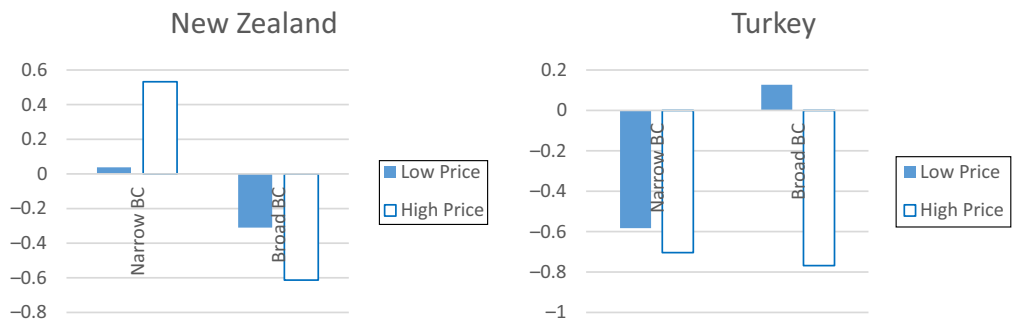
narrow conceptualizers in New Zealand exhibited greater satisfaction $(M=0.20, \mathrm{SD}=1.01$, $\mathrm{N}=54)$ in comparison to those in Turkey $(M=-0.69, \mathrm{SD}=0.98, \mathrm{~N}=86)$ and this difference was significant $[t(138)=5.21, p<0.01]$. In contrast, broad conceptualizers in New Zealand expressed greater dissatisfaction (negative disconfirmation) $(M=-0.50, \mathrm{SD}=1.30$ ) compared to those in Turkey $(M=-0.36, \mathrm{SD}=1.25)$. This difference, however, was not significant $[t(124)=0.58, p=0.56]$.

\section{Discussion and implications}

\subsection{Discussion of the results}

This research shows that effectiveness-centered price placebo is moderated by the nature of BC. In both New Zealand and Turkey, the price placebo effect holds only when the consumer is a narrow conceptualizer of beauty, while this effect does not operate among broad conceptualizers. In regard to the satisfaction-centered price placebo, in New Zealand narrow beauty conceptualizers exhibit positive disconfirmation (excitement), while broad beauty conceptualizers experience negative disconfirmation (dissatisfaction). In Turkey, high price tends to lead to negative disconfirmation for both groups. Regarding cultural differences, in the narrow $\mathrm{BC}$ group New Zealanders reported greater effectiveness and satisfaction compared to Turkish women. In contrast, in the broad BC group, it is Turkish women who perceived greater effectiveness. These results indicate the culturally universal impact of narrow beauty standards promoted by mainstream media: narrow images tend to cloud consumers' rational thinking and make them increasingly susceptible to the biased evaluation of product performance reflected in the price placebo effect. Those women who see beauty as a broad concept (i.e. beyond the outer look) tend to be immune to such bias. Perhaps, consumers need to exercise a greater level of reflexive consumption (Kadirov et al., 2016).

The price placebo theory predicts that individuals use price to infer the effectiveness of a product. From the Islamic methodological perspective, we note that this can be seen as the Sunnah of Allah in action (Kadirov et al., 2020): the psychological mechanism driving the placebo effect credits creative intelligence ingrained in the human brain. If the person has prominent beliefs about how a product will function, the actual performance perception adapts to coincide with such beliefs. As price is used as an indicator for consumers to infer the product's performance, it creates an opportunity for marketers to benefit from. Capitalizing on this psychological behavior, marketers can set high prices to activate the price placebo effect. However, actual performance is not the only effectiveness measure that requires recognition. For some product categories, effectiveness is perceived, while such perceptions become an important cue of product performance. For example, beauty products are assessed via perceptual evaluation (i.e. after using anti-aging products, the skin is perceived to feel softer and the appearance of wrinkles has reduced). This type of product evaluation requires perceptual measures rather than methodical measures. The current study elaborates on this and examines the influence of price on perceptions of effectiveness.

The contribution of this research is that it shows consistent price placebo effects across cultures. This study also focuses on how different ways of conceptualizing beauty affects price-placebo dynamics. Psychologically, the consumer may place more importance on either outer beauty (i.e. narrowly conceptualized beauty) or inner beauty (i.e. broadly conceptualized beauty). When importance is placed on outer beauty, consumers are more influenced by media images, particularly when the images exaggerate physical beauty. On the other hand, those who place importance on inner beauty have a higher likelihood of not being affected by such media communications. Although traditional media consistently adopts an outer beauty approach, recent times have seen a shift in this ideology and a movement toward inner beauty is largely gaining attention. The movement echoes Islamic
Impact of a conceptualization of beauty 
values in a sense that marketers should not excessively manipulate consumers' irrational drives (Kadirov, 2014; Wilson, 2016).

The perceptions of outer beauty significantly contribute to personal physical and mental states (Szabo, 2015). Literature concerning body disorders have highlighted the importance of broadly conceptualizing beauty, as it is a major facet in creating a positive body image (Bailey et al., 2015; Tylka and Iannantuono, 2016; Tylka, 2012; Tylka and Wood-Barcalow, 2015). Psychologically, the impact of a negative perception of the body and distortion of the ideal beauty image can develop into disorders and body image disturbances (Tylka and Iannantuono, 2016; Szabo, 2015) causing individuals to be dissatisfied with their own beauty (Tylka and Iannantuono, 2016; Szabo, 2015). Research has established that not only do such beauty perceptions influence self-esteem but also the self-concept (Szabo, 2015). Studies demonstrate that people who are judged based on outer beauty while being physically attractive are assumed to have more socially desirable characteristics (Dion et al., 1972). Similarly, these people are assumed to be more successful, have happier lives and command greater intelligence (Dion et al., 1972; Kanazawa, 2011).

The same study is extended to include the effect of different cultural perspectives. As a result of globalization, brands continue to penetrate most international markets. Consequently, the marketers of these brands must be aware of cultural values to successfully market to international customers. As beauty is interpreted differently across the world, marketers must ensure that they are aware of which markets will respond favorably to the adoption of an inner beauty approach. For example, studies have established that Asian, colored women and white women respond differently to mainstream beauty standards (Evans and McConnell, 2003). The results of this research partially support these findings, as the differences between New Zealand and Turkey are found to be marginal.

\subsection{Implications}

This study provides valuable insights for both practitioners and academics by focusing on how $\mathrm{BC}$ moderates the effect of price on perceived effectiveness/satisfaction. The previous research did not explore the different variations of price placebo such as effectivenesscentered and satisfaction-centered perceptions. Personal BC is investigated, however, only to some extent within the domain of body image and appreciation research. This study extends these concepts into the Islamic marketing domain. Moreover, providing theoretical contribution, this study is valuable, particularly, to marketers in the beauty industry, as it offers some insights regarding the psychological behavior of the target market. If marketers were aware of different perceptions of beauty and how these influence the price placebo effect, it would allow them to decide what strategies are most appropriate for different groups of customers in different cultural settings. For example, by pursuing the movement toward outer beauty, high-end brands could be compromising opportunities to capitalize on the price placebo effect. To make relevant decisions, marketers will need to know if their products are still being perceived as effective in the functionality and also if consumers are satisfied with changes.

The most prominent managerial implication gained from this research is that marketers might find it viable to continue using traditional media communications with a view of promoting narrow $\mathrm{BC}$ to maximize the placebo effect of price. Particularly, for luxury beauty brands that differentiate themselves based on price inferences, the price placebo theory would be a key theory underpinning business objectives and strategies. As the high priced product creates a placebo effect when beauty is conceptualized narrowly, marketers would find it advantageous to continue to focus on media idealizing outer beauty and set high prices to stimulate the perceptions of greater effectiveness and satisfaction. However, there 
appears to be a boundary condition: broad $\mathrm{BC}$ is a societal counter-force that neutralizes the placebo effect. This counter-force is evident in both Western and Muslim communities.

Another valuable insight gained was that the effect of the (high vs low) price diminishes when expectations are taken into account. The hypotheses concerning the satisfactioncentered placebo effect proposed in this study were not supported. These results provide beneficial insights after the examination of the interaction effects. In New Zealand, satisfaction turns into dissatisfaction as one moves from narrow $\mathrm{BC}$ to broad $\mathrm{BC}$. In Turkey, only the high priced option follows this path, while the low priced option underlies a shift from dissatisfaction to satisfaction as one moves from narrow $\mathrm{BC}$ to broad $\mathrm{BC}$. This demonstrates that in general high price creates higher expectations in both countries, while the low price might create negligible expectations only in Turkey. Therefore, marketers must manage the risk of high expectations when setting prices high.

Overall, it is inevitable that some societies will fundamentally reconsider the ethical underpinnings of conventional media use caused by the portrayal of Western beauty ideals and standards. However, taken at face value, these findings suggest that society's response to such media approaches is counter-reactive. This raises the issue for marketers of whether profitability or ethical responsibility should be prioritized when conducting business. This poses an interesting issue as Dove Beauty, the original initiator of the inner beauty movement has a brand value of US\$4,104m. However, despite this impressive brand value, the brand is the lowest in value among other Unilever subsidiaries. This can be interpreted in two ways; the first interpretation supports the findings of this study where companies focusing on the inner beauty approach may gain less profit as the perceived effectiveness is not greatly observed, which can result in dissatisfaction. On the other hand, the impressive net value may suggest that this inner beauty approach is feasible for well-established companies where other factors such as reputation or person-brand associations may mitigate the consequences observed in this study. This point, however, would require further research.

\subsection{Limitations and directions for future research}

When considering the findings, an important limitation to consider is that the respondents partaking in this experiment were responding based off a hypothetical scenario. The respondents did not physically use the products nor did the hypothetical scenario include the evaluation of the product effect on the self. This limitation is important to consider because it could affect the satisfaction derived from the product. Some consumers may still be satisfied with a product despite it not being effective. This is because other factors can contribute to product satisfaction - such as the symbolic reasons associated with the product or the experiential values gained. To include other factors of satisfaction, an improvement to this study could measure customer satisfaction independently rather than using the equation (satisfaction $=$ effectiveness - expectations).

Another limitation was that respondents were required to have a Facebook account in order to access the survey in New Zealand. It can be argued that it is not a representative sample of the population - which affects the generalizability of the research as the internet population does not accurately reflect the general population (Ilieva et al., 2002). For example, some older generations may be technological novices and may choose to disengage with online activities they are unfamiliar with. Alternatively, they may be willing to participate, however, the survey may not be user-friendly (Ilieva et al., 2002). This limitation further skewed the internet population toward individuals who felt comfortable using technology - proposing an inaccurate representation of the population (Evans and Mathur, 2005). Such trends can be different in different countries, which can complicate the situation even further. However, the justification of continuing to use this channel was on the premise 
that a snowballing effect occurs. Snowballing would occur as respondents refer the survey onwards through additional media such as e-mail or even having friends or family access the survey from their Facebook account.

As mentioned in the implications, one route for future research could investigate the impact of brand equity on the feasibility of adopting the inner beauty movement. This would be beneficial as the existing literature indicates that brand equity can provide value to consumers through brand associations (Aaker, 1992). Aaker further suggests that brand associations result in positive attitudes and feelings toward the brand which can create brand loyalty. If consumers are loyal to a brand, it would be interesting to investigate whether the loyalty will create an insulation effect during rebranding and if these consumers will accept the repositioning strategies and continue to stand by the brand. Furthermore, the literature shows that consumers demonstrate higher levels of brand loyalty as a result of strategic cause-related marketing (supporting social causes i.e. inner beauty and self-body appreciation) so long that the company had a long term commitment to the campaign and it was related to low-involvement products (Van den Brink et al., 2006). As the beauty industry involves high-involvement products, this literature suggests that, perhaps, the long term approach of the inner beauty movement is not ideal in generating brand equity. This aspect needs to be researched further.

\section{References}

Aaker, D.A. (1992), "The value of brand equity”, Journal of Business Strategy, Vol. 13 No. 4, pp. 27-32.

Aoun, I. and Tournois, L. (2015), "Building holistic brands: an exploratory study of halal cosmetics", Journal of Islamic Marketing, Vol. 6 No. 1, pp. 109-132.

Bailey, K.A., Gammage, K.L., van Ingen, C. and Ditor, D.S. (2015), “It's all about acceptance': a qualitative study exploring a model of positive body image for people with spinal cord injury", Body Image, Vol. 15, pp. 24-34.

Borsook, D. and Becerra, L. (2005), "Placebo: from pain and analgesia to preferences and products", Journal of Marketing Research, Vol. 42 No. 4, pp. 394-398.

Business Wire (2015), "Research and markets: global cosmetics market 2015-2020: market was $\$ 460$ billion in 2014 and is estimated to reach $\$ 675$ billion by 2020", available at: www.businesswire.com/news/ home/20150727005524/en/Research-Markets-Global-Cosmetics-Market-2015-2020-Market

Chaudhri, S.K. and Jain, N.K. (2014), "History of cosmetics", Asian Journal of Pharmaceutics, Vol. 3 No. 3, p. 164.

Cook-Cottone (2015), "Incorporating positive body image into the treatment of eating disorders: a model for attunement and mindful self-care”, Body Image, Vol. 14, pp. 158-167.

Coulter, R.A., Price, L.L. and Feick, L. (2003), "Rethinking the origins of involvement and brand commitment: insights from postsocialist Central Europe", Journal of Consumer Research, Vol. 30 No. 2, pp. 151-169.

Crawford, S.D., Couper, M.P. and Lamias, M.J. (2001), "Web surveys: perceptions of burden”, Social Science Computer Review, Vol. 19 No. 2, pp. 146-162.

Dion, K., Berscheid, E., Walster, E. and Lanzetta, J.T. (1972), "What is beautiful is good”, Journal of Personality and Social Psychology, Vol. 24 No. 3, pp. 285-290.

Duan, N. (2015), "Six empowering beauty campaigns that prove beauty isn't just skin deep", available at: www.yahoo.com/lifestyle/six-empowering-beauty-campaigns-that-prove-beauty-110642145568.html

Evans, J.R. and Mathur, A. (2005), "The value of online surveys", Internet Research, Vol. 15 No. 2, pp. 195-219.

Evans, P. and McConnell, A.R. (2003), "Do racial minorities respond in the same way to mainstream beauty standards? Social comparison processes in Asian, black, and white women", Self and Identity, Vol. 2 No. 2, pp. 153-167. 
Fearon, C. and Philip, G. (2008), "Measuring success of electronic trading in the insurance industry: operationalising the disconfirmation of expectations paradigm", Behaviour and Information Technology, Vol. 27 No. 6, pp. 483-493.

French, C. (2004), “The history of makeup”, available at: www.authorsden.com/visit/viewArticle.asp? id $=15438$

Fried, O., Jacobs, J., Finkelstein, A. and Agrawala, M. (2020), "Editing self-image”, Communications of the Acm, Vol. 63 No. 3, pp. 70-79.

Geers, A., Weiland, P., Kosbab, K., Landry, S., Helfer, S. and Devine, P. (2005), "Goal activation, expectations, and the placebo effect”, Journal of Personality and Social Psychology, Vol. 89 No. 2, pp. 143-159.

Gliem, R. and Gliem, J. (2003), "Calculating, interpreting, and reporting cronbach's alpha reliability coefficient for likert-type scales", Midwest Research-to-Practice Conference in Adult, Continuing, and Community Education.

Hargreaves, D. and Tiggemann, M. (2002), "The effect of television commercials on mood and body dissatisfaction: the role of appearance-schema activation", Journal of Social and Clinical Psychology, Vol. 21 No. 3, pp. 287-308.

Havlin, N. and Báez, J.M. (2018), "Introduction: revisiting beauty”, WSQ: Women's Studies Quarterly, Vol. 46 Nos 1/2, pp. 13-24.

Hayes, A.F. (2013), Introduction to Mediation, Moderation, and Conditional Process Analysis, Guilford Press, New York, NY.

Higie, R.A. and Feick, L.F. (1989), Enduring Involvement: Conceptual and Measurement Issues, ACR North American Advances.

Huffington Post (2014), "Dove 'real beauty' campaign turns 10: how a brand tried to change the conversation about female beauty", available at: www.huffingtonpost.com/2014/01/21/dove-realbeauty-campaign-turns-10_n_4575940.html

Ilieva, J., Baron, S. and Healey, N.M. (2002), "Online surveys in marketing research: pros and cons", International Journal of Market Research, Vol. 44 No. 3, pp. 361-376.

Irmak, C., Block, L. and Fitzsimons, G. (2005), "The placebo effect in marketing: sometimes you just have to want it to work", Journal of Marketing Research, Vol. 42 No. 4, pp. 406-409.

Kadirov, D. (2014), "Islamic marketing as macromarketing", Journal of Islamic Marketing, Vol. 5 No. 1, pp. 2-19.

Kadirov, D. (2018), "Towards a theory of marketing systems as the public good", Journal of Macromarketing, Vol. 38 No. 3, pp. 278-297.

Kadirov, D., Allayarova, N. and Boulanouar, A.W. (2016), "Transformation as reversion to Fitrah: Muslim māori women's self-transformation through reflexive consumption", Journal of Business Research, Vol. 69 No. 1, pp. 33-44.

Kadirov, D., Bahiss, I. and Bardakc1, A. (2020), "Causality in islamic marketing research: building consistent theories and stating correct hypotheses", Journal of Islamic Marketing, doi: 10.1108/ JIMA-05-2019-0113.

Kanazawa, S. (2011), "Intelligence and physical attractiveness", Intelligence, Vol. 39 No. 1, pp. 7-14.

Kirsch, I. (1985), "The logical consequences of the common-factor definition of the term placebo", American Psychologist, Vol. 40 No. 2, pp. 237-238.

Kirsch, I. and Sapirstein, G. (1998), "Listening to prozac but hearing placebo: a meta-analysis of antidepressant medication", Prevention and Treatment, Vol. 1 No. 2, p. 2a.

Kleijnen, M., De Ruyter, K. and Wetzels, M. (2007), "An assessment of value creation in mobile service delivery and the moderating role of time consciousness", Journal of Retailing, Vol. 83 No. 1, pp. 33-46. 
Leavitt, H.J. (1954), "A note on some experimental findings about the meanings of price", The Journal of Business, Vol. 27 No. 3, pp. 205-210.

Lenth, R.V. (2001), "Some practical guidelines for effective sample size determination", The American Statistician, Vol. 55 No. 3, pp. 187-193.

Lichtenstein, D.R. and Burton, S. (1989), "The relationship between perceived and objective pricequality", Journal of Marketing Research, Vol. 26 No. 4, pp. 429-443.

Lifecellproducts (2013), "How much should your anti-Aging cream cost?", available at: http:// lifecellproducts.com/how-much-should-anti-aging-cream-cost/

Litman, T. (2004), "Transit price elasticities and cross-elasticities", Journal of Public Transportation, Vol. 7 No. 2, p. 3.

McKelle, E. (2015), "9 Body positive social media campaigns that are changing how we perceive beauty both in and outside the fashion world", available at: www.bustle.com/articles/75539-9-bodypositive-social-media-campaigns-that-are-changing-how-we-perceive-beauty-both-in-and

MacCallum, F. and Widdows, H. (2018), "Altered images: understanding the influence of unrealistic images and beauty aspirations", Health Care Analysis, Vol. 26 No. 3, pp. 235-245.

Micu, C.C., Coulter, R.A. and Price, L.L. (2009), "How product trial alters the effects of model attractiveness", Journal of Advertising, Vol. 38 No. 2, pp. 69-82.

Montgomery, G. (1997), "Classical conditioning and the placebo effect”, Pain, Vol. 72 No. 1, p. 107.

Montgomery, G. and Kirsch, I. (1996), "Mechanisms of placebo pain reduction: an empirical investigation", Psychological Science, Vol. 7 No. 3, pp. 174-176.

NZ Herald (2015), "How many kiwis use facebook?”, available at: www.nzherald.co.nz/business/news/ article.cfm?c_id=3\&objectid $=11436706$

Owens, V.R. (2016), "Grandma got run over by the fashion industry: an analysis of the negative effects of Western hegemonic beauty standards on women 60+", Honors Thesis, available at: https:// digitalcommons.lmu.edu/honors-thesis/117

Palmer, D. and Hedberg, T. (2013), "The ethics of marketing to vulnerable populations", Journal of Business Ethics, Vol. 116 No. 2, pp. 403-413.

Price, D., Finniss, D. and Benedetti, F. (2008), "A comprehensive review of the placebo effect: Recent advances and current thought”, Annual Review of Psychology, Vol. 59 No. 1, pp. 565-590.

Rajanala, S., Maymone, M.B.C. and Vashi, N.A. (2018), Selfies - Living in the Era of Filtered Photographs, JAMA Facial Plast Surg, 10.1001/jamafacial.2018.0486

Roggeveen, A.L., Bharadwaj, N. and Hoyer, W.D. (2007), "How call center location impacts expectations of service from reputable versus lesser known firms", Journal of Retailing, Vol. 83 No. 4, pp. 403-410.

Santos, J. and Boote, J. (2003), "A theoretical exploration and model of consumer expectations, post-purchase affective states and affective behaviour", Journal of Consumer Behaviour, Vol. 3 No. 2, pp. 142-156.

Saunders, J.B., Aasland, O.G., Babor, T.F., De la Fuente, J.R. and Grant, M. (1993), "Development of the alcohol use disorders identification test (AUDIT): WHO collaborative project on early detection of persons with harmful alcohol consumption-II", Addiction, Vol. 88 No. 6, pp. 791-804.

Scherker, A. (2014), "7 ways the beauty industry convinced women that they weren't good enough", available at: www.huffingtonpost.com/2014/04/29/beauty-industry-women_n_5127078.html

Shiv, B., Carmon, Z. and Ariely, D. (2005), "Placebo effects of marketing actions: consumers may get what they pay For", Journal of Marketing Research, Vol. 42 No. 4, pp. 383-393.

Sölle, A., Bartholomäus, T., Worm, M. and Klinger, R. (2014), "How to psychologically minimize scratching impulses: benefits of placebo effects on itching using classical conditioning and expectancy", Zeitschrift Für Psychologie, Vol. 222 No. 3, pp. 140-147.

Statista (2008), "Cosmetics industry - statistics and facts", available at: www.statista.com/topics/3137/ cosmetics-industry/ 
Statistics New Zealand (2013), "Household use of information and communication technology: 2012”, available at: http://archive.stats.govt.nz/browse_for_stats/industry_sectors/ information_technology_and_communications/HouseholdUseofICT_HOTP2012.aspx

Stewart-Williams, S. (2004), "The placebo puzzle: putting together the pieces. Health psychology: official journal of the division of health psychology", Health Psychology, Vol. 23 No. 2, pp. 198-206.

Stewart-Williams, S. and Podd, J. (2004), "The placebo effect: dissolving the expectancy versus conditioning debate", Psychological Bulletin, Vol. 130 No. 2, pp. 324-340.

Suciu, L., Mortan, M. and Lazar, L. (2013), "Vroom's expectancy theory. An empirical study: civil servant's performance appraisal influencing expectancy", Transylvanian Review of Administrative Sciences, No. 39, p. 180.

Szabo, M. (2015), "The relationship between body image and self-esteem”, European Psychiatry, Vol. 30, p. 1354.

Thompson, V. (2020), "Influence of advertisement on women and the attitude toward cosmetics", available at: http://smallbusiness.chron.com/influence-advertisement-women-attitude-toward-cosmetics-69974.html

Tylka, T. (2012), "Positive psychology perspectives on body image A2 - cash", Thomas Encyclopedia of Body Image and Human Appearance, Academic Press, Oxford, pp. 657-663.

Tylka, T.L. and Iannantuono, A.C. (2016), "Perceiving beauty in all women: Psychometric evaluation of the broad conceptualization of beauty scale", Body Image, Vol. 17, pp. 67-81.

Tylka, T. and Wood-Barcalow, N. (2015), "The body appreciation scale-2: item refinement and psychometric evaluation", Body Image, Vol. 12, pp. 53-67.

Tylka, T. and Wood-Barcalow, N. (2015), "What is and what is not positive body image? Conceptual foundations and construct definition [special series"], Body Image, Vol. 14, pp. 118-129.

Van den Brink, D., Odekerken-Schröder, G. and Pauwels, P. (2006), "The effect of strategic and tactical cause-related marketing on consumers' brand loyalty", Journal of Consumer Marketing, Vol. 23 No. 1, pp. 15-25.

Vase, L., Robinson, M.E., Verne, G.N. and Price, D.D. (2003), "The contributions of suggestion, desire, and expectation to placebo effects in irritable bowel syndrome patients: an empirical investigation", Pain, Vol. 105 No. 1, pp. 17-25.

Voss, K.E., Spangenberg, E.R. and Grohmann, B. (2003), "Measuring the hedonic and utilitarian dimensions of consumer attitude", Journal of Marketing Research, Vol. 40 No. 3, pp. 310-320.

Wilson, J.A.J. (2016), "Marketing modest fashion or fashioning modesty?”, Maestro, pp. 89-91.

Yan, Y. and Bissell, K. (2014), "The globalization of beauty: how is ideal beauty influenced by globally published fashion and beauty magazines?", Journal of Intercultural Communication Research, Vol. 43 No. 3, pp. 194-214.

Zaichkowsky, J.L. (1994), “The personal involvement inventory: reduction, revision, and application to advertising", Journal of Advertising, Vol. 23 No. 4, pp. 59-70.

Zehrer, A., Crotts, J.C. and Magnini, V.P. (2011), "The perceived usefulness of blog postings: an extension of the expectancy-disconfirmation paradigm”, Tourism Management, Vol. 32 No. 1, pp. 106-113.

\section{Corresponding author}

Djavlonbek Kadirov can be contacted at: djavlonbek.kadirov@vuw.ac.nz

For instructions on how to order reprints of this article, please visit our website:

www.emeraldgrouppublishing.com/licensing/reprints.htm

Or contact us for further details: permissions@emeraldinsight.com 